\title{
Apresentação: educação e design, um (des)encontro possível?
}

\author{
Marcos Beccari ${ }^{1}$
}

\section{Ensino do design e ensino em design}

No contexto brasileiro, o ensino do design possui uma história recente (a partir dos anos 1930) e, de modo geral, tem se deslocado da ênfase da prática profissional para a da pesquisa científica. Em março de 2004, foi realizado em São Paulo o I Seminário sobre o Ensino do Design, que contou com conferências de professores reconhecidos no campo, como Gui Bonsiepe e Enzo Mari (Cf. ARAÚJO, 2004). Desde então, ampliou-se a reflexão sobre o ensino do design e a formação do designer no Brasil: projetos educacionais, estruturas curriculares, estratégias e reformas pedagógicas (Cf. COUTO, 2008). Boa parte dessas discussões pautou-se no esforço de ponderar sobre as múltiplas definições do design e do profissional de design mediante as leis brasileiras que regem o ensino superior. ${ }^{2}$

A proposta do $1^{\circ} \mathrm{SED}$ - Seminários sobre Ensino em Design, no entanto, possui outro foco: em vez de "ensino do design", a ideia foi discutir sobre o ensino em design. A diferença é entre uma perspectiva específica, a do design, e uma visada que abranja simultaneamente os campos da educação e do design. A escolha pelo segundo enfoque se deve, em primeiro lugar, ao contexto do evento: trata-se da apresentação dos resultados da disciplina de Metodologia do Ensino Superior, que eu ministro no Programa de Pós-Graduação em Design da UFPR.

Em segundo lugar, a dificuldade que os designers enfrentam para lidar com desafios e perspectivas do ensino procede, a meu ver, da falta de distanciamento crítico em relação aos problemas específicos do design. Tais problemas específicos, afinal, tornam-se imprecisos não apenas mediante a diversidade de cursos de design que proliferam no país, mas sobremaneira pelas polarizações da educação brasileira (pública x privada, formal x informal) e pelas diferentes tendências pedagógicas.

Não significa, porém, que as questões próprias do design não tenham importância alguma no ensino. Significa que o ensino não se reduz ao conteúdo do que é ensinado. Trata-

\footnotetext{
${ }^{1}$ Professor permanente do PPG-Design da Universidade Federal do Paraná (UFPR). Doutor em Educação pela Universidade de São Paulo (USP). E-mail: contato@marcosbeccari.com.

${ }^{2} \mathrm{O}$ que vem expresso repetidamente em todos os documentos legais que versam sobre educação (desde a Constituição Federal de 1988, passando pela Lei de Diretrizes e Bases, PNEs etc.) pode ser traduzido em "cidadania e inserção no mundo do trabalho".
} 
se de reconhecer, para além de procedimentos formais como currículo e planos de ensino, a riqueza e a complexidade da prática docente, as tensões e conexões entre concepções distintas de formação. No cotidiano acadêmico, tais questões subsistem numa zona de sombra, de modo secundário em relação às demandas institucionais. Trazer à luz tal problemática é a estratégia que eu adoto na disciplina supracitada: questionar a todo instante os motivos e as finalidades do ensino.

\section{Questões sobre o ensino}

Ensina-se para quê? Para a transformação da sociedade? Para a inserção no mercado de trabalho? Para uma formação humana e cultural? Tudo isso e mais um pouco, no discurso. Uma geração busca formar novas gerações para dar conta das questões que ainda não foram resolvidas. Na prática, contudo, trata-se de um jogo "bancário", conforme a célebre analogia de Paulo Freire: o professor é o credor e o aluno o devedor. Após pagar para ter aula, o depositante obtém seu extrato por meio da avaliação, que quantificará os lucros e prejuízos de seu investimento.

Ensina-se, pois, para validar o próprio ensino. Os professores ensinam e avaliam necessariamente a partir de suas expectativas de resposta, seja no plano moral (interesse, empenho, boas intenções etc.), seja no plano utilitário (cálculo moral). Com efeito, aos alunos são dispostos os erros, os acertos, o desempenho, o diagnóstico (o que foi aprendido e o que não foi), o dado quantitativo (a nota, o conceito, o percentual de aproveitamento) e também o dado qualitativo (sua participação em sala, se é dedicado, esforçado, interessado, dócil). O ponto é que, com isso, aprendemos a seguir algum padrão que nos permita reconhecer as coisas como válidas ou mesmo verdadeiras.

No ensino do design, narra-se, por exemplo, uma ou outra versão da história do design, em vez de se discutir o que é fazer história. São estabelecidos critérios de legibilidade e composição visual, em vez de se explorar desvios e gostos estéticos. Receitam-se métodos projetuais, em vez de se problematizar a própria lógica de resolução de problemas. Recomenda-se fundamentar um trabalho por meio de verdades "comprovadas cientificamente", em vez de se discutir o que significa ciência, quais seus impasses e limites. Ensina-se, enfim, o design como um conjunto de saberes estáveis, coisa que a ciência busca combater desde seus primórdios. 
Quando falamos de ensino em design, por sua vez, não se trata de pensar em reformas curriculares, no enunciado das ementas, em carga horária etc. Embora esses aspectos devam, em cada contexto institucional, ser repensados continuamente, aqui importa mais refletir sobre o que significa ensinar e aprender. Há que se discutir, portanto, o papel do professor, se sua autoridade é pautada no domínio do conteúdo, na técnica, no método, na didática com que conduz suas aulas, se está centrada na imposição de um título ou apenas na relação particular com cada aluno. Há também que se discutir como os alunos enxergam a si mesmos: como um coro em uníssono ou como um grupo de afinidades, descompassos e dissonâncias.

É interessante pensar, nesse ínterim, sobre o discurso consensual e ao mesmo tempo incógnito acerca da vida estudantil. Todos concordam que a depressão, o uso de drogas, a violência e a diversidade de gêneros, por exemplo, são questões sociais das mais relevantes, mas em sala de aula é como se elas não existissem:

A diversidade sexual é aceita, no discurso. O uso de drogas deve ser rechaçado, no discurso. A violência está do lado de fora dos portões, devidamente guardados por cadeados. Sim, no discurso somente. Na prática, há alunos GLBT (camuflados), há usuários de drogas (camuflados), e um grande número em potencial, e sim, há violência (explícita e implícita, física e psicológica), entre alunos, de alunos a professores e destes àqueles. Pois a própria estrutura repressiva, opressora, moralista da escola é violenta. Discurso para um lado, prática para o outro. (FERREIRASANTOS; ALMEIDA, 2011, p. 269)

Algo similar ocorre nos discursos sobre "neutralidade" política, ideológica e religiosa em sala de aula. De um lado, defende-se a pluralidade de ideias no ambiente acadêmico; de outro, determinados assuntos são vetados justamente em nome da pluralidade de ideias (?). Tal proeza já foi instituída em 1968, quando os militares importaram o modelo norteamericano de ensino profissionalizante e tecnicista ${ }^{3}$ - acarretando, dentre outras consequências, a estagnação da pesquisa científica. De lá pra cá foi mantida a prioridade educacional no tocante ao desenvolvimento econômico e social do país; donde o ensino superior como mecanismo básico de ascensão socioeconômica para os que dele usufruem.

\footnotetext{
${ }^{3}$ Cf. ibidem, p. 111-124. Cf. ainda: ROMANELLI, 1988, p. 193-227; FREITAG, 1986, p. 73-124.
} 


\section{Impassess e desencontros}

O que vemos hoje nos cursos de design é um duplo imperativo: ensino profissionalizante $e$ voltado à pesquisa, o que muitas vezes não significa nem uma coisa nem outra. É patente, nesse sentido, um superávit de expectativas e queixas: de um lado, espera-se que tudo seja ensinado (habilidades práticas, competências intelectuais, valores, métodos etc.); de outro, já não se consegue ensinar quase nada, dada a imprecisão irrefletida dos papéis de professor e aluno e, por extensão, a esgarçadura dos vínculos entre eles.

Muitos professores se perguntam: se o desinteresse dos alunos é cada vez maior, qual o sentido de nossos esforços? Muitos alunos se indagam: se os professores desconhecem nossos interesses, qual a razão para levá-los a sério?

O resultado desse desencontro é, primeiro, a experiência solitária dos atores em sala de aula e, depois, a formação de um contingente de mão-de-obra cuja parcela ociosa, ao ingressar no magistério, perpetua, de novo e de novo, aquele mesmo desencontro. Afinal, o paradigma que norteia a profissionalização do professorado em design ainda é o da formação especializada, ${ }^{4}$ tendo como premissa a concepção tradicional e meramente técnica de "transmissão do conhecimento", além de contar com certa "maturidade" dos alunos para responder às exigências de um ensino alicerçado nos rigores científicos. Claro que, em contrapartida, na recente literatura do design encontramos diversos sinais de esforço para a formação de um profissional com maior autonomia crítica. Difícil é encontrar uma autocrítica: qual professor é capaz de questionar, em sala de aula, o que ele mesmo ensina?

Ilustremos tal dificuldade. Em seu Design para um mundo complexo, Rafael Cardoso propõe que pensemos o ensino do design para além de suas manifestações específicas e das práticas de determinado indivíduo ou escola. No entanto, quando o autor sinaliza algum caminho para isso, acaba por contradizer-se: “A formação de um designer pensante - legado de Ulm - ainda é uma meta a ser perseguida" (CARDOSO, 2012, p. 241). Ora, por que um "designer pensante", na qualidade de quem pensa por si mesmo, depende de um legado a ser perseguido? E como se ensina alguém a "pensar por si mesmo"?

Nos cursos de filosofia, por exemplo, essa tarefa se mostra mais complexa: de acordo com o prof. Ricardo Terra (FFLCH-USP), “[...] se formam aqui historiadores da filosofia, e não filósofos" (TERRA, 2010, p. 25). Com isso podemos perceber que, mais do que ensinar a

\footnotetext{
${ }^{4}$ A exemplo de uma tese de doutorado apresentada em 1974 na Universidade de Michigan, cujo título é "Avaliação de treze tipos de capacetes de futebol à base de certas medidas de impacto" (apud SAVIANI, 1991, p. 120).
} 
pensar, importa-nos colocar em questão a própria importância do "pensar": por que é preciso ensinar e aprender a pensar? As pessoas não sabem pensar por conta própria? O que significa esse anseio, essa esperança, essa determinada forma de "pensar" que norteia o ensino, seus processos e agentes? E por que buscar novas respostas para velhas perguntas, novos pensamentos para tratar de antigos impasses?

\section{Um convite ao diálogo}

Tais impasses e questões em aberto servem-nos para apontar a complexidade do ensino em design, que ultrapassa a área restrita do ensino do design.

\footnotetext{
Os impasses que os professores enfrentam cada vez menos dizem respeito ao domínio do conteúdo de suas matérias de ensino, ainda que reconheçam nele uma condição fundamental de seu trabalho. Os desafios atuais da docência universitária parecem estar requerendo saberes que até então representam baixo prestígio acadêmico no cenário das políticas globalizadas, porque extrapolam a possibilidade de quantificar produtos. (CUNHA, 2004, p. 533)
}

Eis o pano de fundo que circunscreve o $1^{\circ} \mathrm{SED}$ - Seminários sobre ensino em design da UFPR. A iniciativa de organizar um evento aberto ao público - que partiu dos alunos, muitos dos quais atuam como professores - teve o intuito de fomentar, por meio de apresentações orais e debates, a troca de experiências e reflexões sobre o ensino superior no contexto do Design. Trabalhar com o diálogo, a troca e a colaboração no ensino superior continua sendo um grande desafio, em contraposição à lógica dominante da produtividade competitiva. Esforços coletivos servem não apenas para validar métodos, estratégias e conhecimentos, mas também para tratar de questões em comum, tais como: em que medida é possível atender as expectativas dos alunos e, ao mesmo tempo, as exigências institucionais? Como motivar os alunos a extrapolarem a mera "transmissão de conhecimento" e a "preparação para o mercado" - premissas pragmáticas que já perfazem suas expectativas? Como, em contrapartida, podemos garantir conhecimentos que lhes permitam percorrer a trajetória prevista pelo currículo? De que maneira é possível aliar ensino e pesquisa?

No âmbito do ensino em design, afinal, para além de funções normativas, abstratas e prescritivas, temos a emergência de professores e alunos em suas próprias narrativas. São 
olhares que, intrinsecamente imiscuídos, tecem um mesmo desencontro, um antigo distanciamento sem o qual não haveria educação possível:

[...] só pode haver educação onde houver gerações em confronto. De um lado, o mais velho lutando para impor um olhar voltado ao passado, um olhar vagaroso e atento aos detalhes do mundo. De outro, o mais novo lutando com todas as forças para não deixar macular seu olhar inaugural sobre a vida, um olhar quase sempre plasmado no presente e suas urgências. (AQUINO, 2009, p. 43)

\section{Referências}

AQUINO, J. G. Docência, poder e liberdade: dos processos de governamentalização à potência de existir nas escolas. Tese de Livre-Docência em Filosofia da Educação. Faculdade de Educação da Universidade de São Paulo, 2009.

ARAÚJO, E. F. Implementação e Reforma do Design no Brasil. Galáxia, n. 7, p. 175-180, abr. 2004

CARDOSO, R. Design para um mundo complexo. São Paulo: Cosac Naify, 2012.

COUTO, R. M. S. Escritos sobre Ensino de Design no Brasil. Rio de Janeiro: Rio Books, 2008 .

CUNHA, M. I. da. Diferentes olhares sobre as práticas pedagógicas no Ensino Superior: a docência e sua formação. Revista Educação, ano XXVII, v. 3, n. 54, p. 525-536, set./dez. 2004

FERREIRA-SANTOS, M.; ALMEIDA, R. de. Antropolíticas da Educação. São Paulo: Képos, 2011.

FREITAG, B. Escola, Estado \& Sociedade. São Paulo: Editora Moraes, 1986.

ROMANELLI, O. O. História da Educação Brasileira (1930/1973). Petrópolis: Vozes, 1988.

SAVIANI, D. Educação e questões da atualidade. São Paulo: Cortez, 1991.

TERRA, R. Não se pode aprender filosofia, pode-se apenas aprender a filosofar. Discurso: Revista do Departamento de Filosofia da USP, n. 40, p. 9-43, 2010. 